\title{
Are African primary physicians suspicious enough? Challenges of multiple myeloma diagnosis in Africa
}

\author{
Erick Thokerunga ${ }^{1 *}$, Christopher Ntege ${ }^{2}$ and Abdullahi Omar Ahmed ${ }^{3}$
}

\begin{abstract}
Background: Multiple myeloma is a hematological malignancy of plasma cells belonging to a spectrum of monoclonal protein-secreting disorders known as paraproteinemias. It is classically characterized by accumulated plasma cells in the bone marrow, renal insufficiency, hypercalcemia, and bone lesions (CRAB). Despite studies in the USA indicating that the incidence of multiple myeloma is twice as much in Americans of African descent compared to white Americans and those of Asian descent, African countries have some of the lowest incidence rates and prevalence of the cancer. It is generally thought that this is not entirely factual given the paucity of research into the cancer in sub-Saharan Africa, coupled with other diagnostic challenges such as economic hardships, and poor health-seeking behaviors. In this mini review, we explored the state of multiple myeloma diagnosis across sub-Saharan Africa, outlining the challenges to diagnosis and proposing possible solutions.

Main body: Due to the lack of routine checkups in people $>40$ years across sub-Saharan Africa, monoclonal gammopathy of undetermined significance (MGUS) and smoldering multiple myeloma (SMM) are often accidentally diagnosed. This is due to a very low awareness of multiple myeloma among primary care clinicians and the general population. Other major challenges to multiple myeloma diagnosis across Africa include a chronic shortage of human resource (pathologists, cytotechnologists, and histotechnologists), and a prohibitive cost of diagnostic services that discourages early diagnosis.

Conclusion: To improve multiple myeloma diagnosis in Africa, a systems approach to thinking among policy makers, philanthropic organizations, and oncologists must be adopted. Governments must invest in health insurance coverage for cancer patients concurrently with heavy investments in human resource training and diagnostic infrastructure scale up. Creative approaches such as digital pathology, online training of clinicians, research and capacity building collaborations among African institutions, European and American institutions, and pharmaceutical companies as seen with other cancers should be explored for multiple myeloma too.
\end{abstract}

Keywords: Myeloma, Suspicious, Clinicians, Challenges, Africa

*Correspondence: erickthokerunga@whu.edu.cn; eriku04@gmail.com

${ }^{1}$ Program and Department of Clinical Laboratory Medicine, Center for Gene Diagnosis, Zhongnan Hospital of Wuhan University,

Wuhan 430071, China

Full list of author information is available at the end of the article

\section{Background}

Multiple myeloma (MM) is a hematological malignancy of plasma cells characterized by the accumulation of clonal plasma cells in the bone marrow, raised calcium in blood, renal impairment, anemia, and bone lesions [1,2]. It belongs to a spectrum of monoclonal protein-secreting disorders known as paraproteinemias, starting off as a small benign monoclonal gammopathy of unknown significance (MGUS), progressing to smoldering multiple 
myeloma (SMM) and finally symptomatic myeloma (Fig. 1). Approximately $1 \%$ of patients with MGUS progress to symptomatic myeloma per year while between 10 and $20 \%$ of patients with SMM progress to symptomatic myeloma per year [4].

MM constitutes $1 \%$ of all cancers globally and accounts for over 10\% of hematological cancers [5]. Across Africa, the incidence of MM per 100,000 population ranges from 0.44 in the eastern region to 2.14 in the southern region [6] (Table 1).

Studies from the USA show that MM disproportionately affects black Americans more compared to Caucasians and people of Asian descent. Cohen et al. [8] reported that the prevalence of MM among black Americans was $8.4 \%$ compared to $3.8 \%$ among whites, while Singh et al. [9] found out that the overall prevalence of MGUS was $14.8 \%$ among black Americans compared to $7.8 \%$ among whites. In fact, the black versus white disparity was more pronounced at a younger age where MGUS was about fourfold higher in the black population compared to matched white counterparts. Moreover, MM is the most common hematological malignancy among black Americans $[10,11]$. In a much larger 16-year study on MGUS, it was discovered that the age adjusted prevalence of MGUS was threefold higher in black Americans compared to whites. However, the cumulative risk of developing MM estimated over the first 10 years of follow-up showed no difference between the two races. So,
Table 1 Multiple myeloma incidence by region across Africa as of December 2020

\begin{tabular}{llll}
\hline Region & Total cases & Population & $\begin{array}{l}\text { Incidence rate } \\
\text { per 100,000 } \\
\text { population }\end{array}$ \\
\hline Southern & 1294 & $60,425,000$ & 2.14 \\
Northern & 2597 & $210,002,000$ & 1.2 \\
Central & 930 & $135,750,000$ & 0.68 \\
Western & 1604 & $331,255,000$ & 0.48 \\
Eastern & 1649 & $373,202,000$ & 0.44 \\
\hline
\end{tabular}

List of the African regions and population got from the World Health Organization database [7]

the increased risk for MM among the black Americans resulted from increase in the risk of MGUS rather than increase in the risk of progressing from MGUS to MM [12].

To date, there is not a strong causal link between the black race and MM. Studies have suggested genetic links, autoimmune diseases or certain infectious diseases and toxins but all suffer from low sample sizes, or low response rate from first-degree relatives of $\mathrm{MM}$ patients, hence, could not independently link these factors to MM [13-23]. In support of the findings from the USA, studies conducted elsewhere in Ghana showed that the prevalence of MGUS was $5.84 \%$ compared to $2.97 \%$ in a reference white population [24]. Further studies

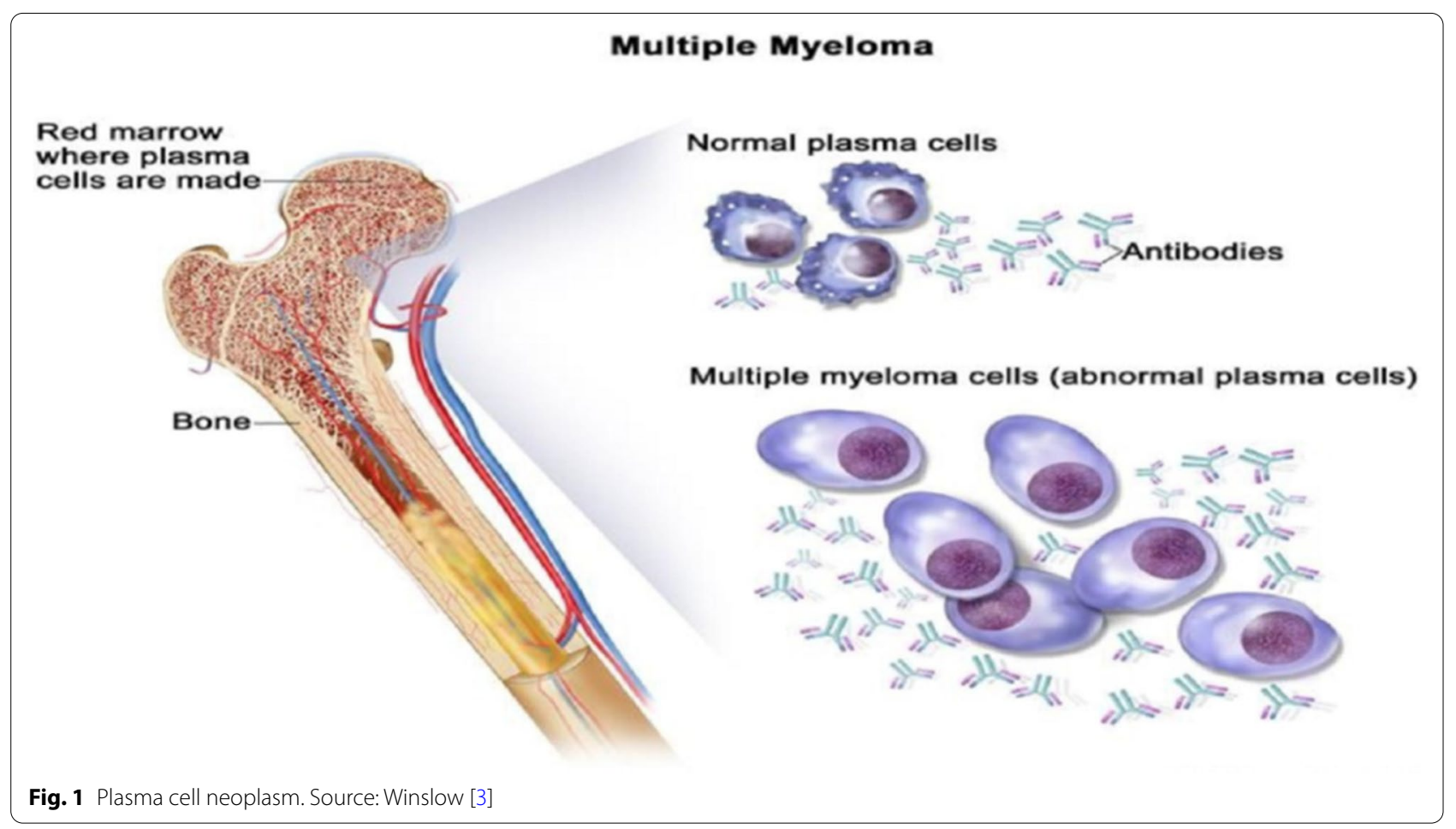


conducted in Martinique in the Caribbeans, whose population is predominantly of African descent showed that it has the second highest prevalence of MM in the black population after the USA [11]. Despite these stark racial disparities in the prevalence of MM, Sub-Saharan African countries still have some of the lowest incidence rates and prevalence of MM compared to countries in Asia, Europe, and the Americas [25], something of a contradiction to the emerging facts. It is often suspected that the true prevalence of all cancers, including $\mathrm{MM}$ on the continent, is grossly underestimated. A 2018 report, on the global incidence of $\mathrm{MM}$, revealed that missed diagnosis and poor record keeping were the major cause of the observed low prevalence in most countries [25]. Before March 2012, only three population-based cancer registries existed in the entire Sub-Saharan Africa (Gambia, Harare, and Kampala), covering $1 \%$ of the population compared to the USA where $80 \%$ of the population are covered by up-to-date registries [26]. The African cancer registry network (AFCRN) presently with 46 member countries in Africa has been created to provide leadership and technical support for cancer surveillance across the continent; however, not all the 52 African countries have joined, and given its heavy reliance on donor funding, long-term sustainability remains a challenge worth looking into [27].

Data from the last two decades on the trends in the incidence of MM in Sub-Saharan Africa over time is hardly available. In the absence of MM data, parallels can be drawn with trends in other cancers prevalent on the continent. Data published by Hamidi and colleagues [28] showed that there is a transient increase in the incidence rates of most of the cancers on the continent as awareness and diagnostic capacity improves
(Fig. 2). This is likely true for multiple myeloma (MM) as well. In fact, recent studies from across the continent though sporadic, present data indicating a gradual increase in $\mathrm{MM}$ incidence. For instance, in Nigeria, MM now accounts for over $8.2 \%$ of all hematological cancers, while in Uganda, between 1991 and 1995, 1996 and 2001, and 2002 and 2006, there has been a progressive increase in incidences from 0.4 to 0.7 to 0.9 (per 100,000 ) in men and 0.5 to 0.9 to 1.7 (per 100,000) in women respectively $[29,30]$. Therefore, with improved $\mathrm{MM}$ awareness among the general population and physicians, improved diagnostic capacities will have notification of more cases.

\section{Multiple myeloma standard diagnostic criteria}

According to the revised International Myeloma Working Group (IMWG) criteria for the diagnosis of MM, in addition to the classical CRAB (calcium elevation, renal damage, anemia, and bone disease), new features have been added for consideration in the final diagnosis. The new definition of an active myeloma is therefore as presented in Fig. 3.

In addition, MGUS and smoldering multiple myeloma are also defined. MGUS is diagnosed as follows: Serum monoclonal protein $<30 \mathrm{~g} / \mathrm{L}$, clonal bone marrow plasma cells $<10 \%$, and the absence of end-organ damage such as hypercalcemia, renal insufficiency, anemia, and bone lesions (CRAB) or amyloidosis attributable to the plasma cell proliferative disorder. Smoldering MM meanwhile is defined as serum monoclonal protein (IgG or IgA) $\geq$ $30 \mathrm{~g} / \mathrm{L}$ or urinary monoclonal protein $\geq 500 \mathrm{mg}$ per 24 $\mathrm{h}$ and/or clonal bone marrow plasma cells $10-60 \%$, and absence of myeloma-defining events or amyloidosis [31].

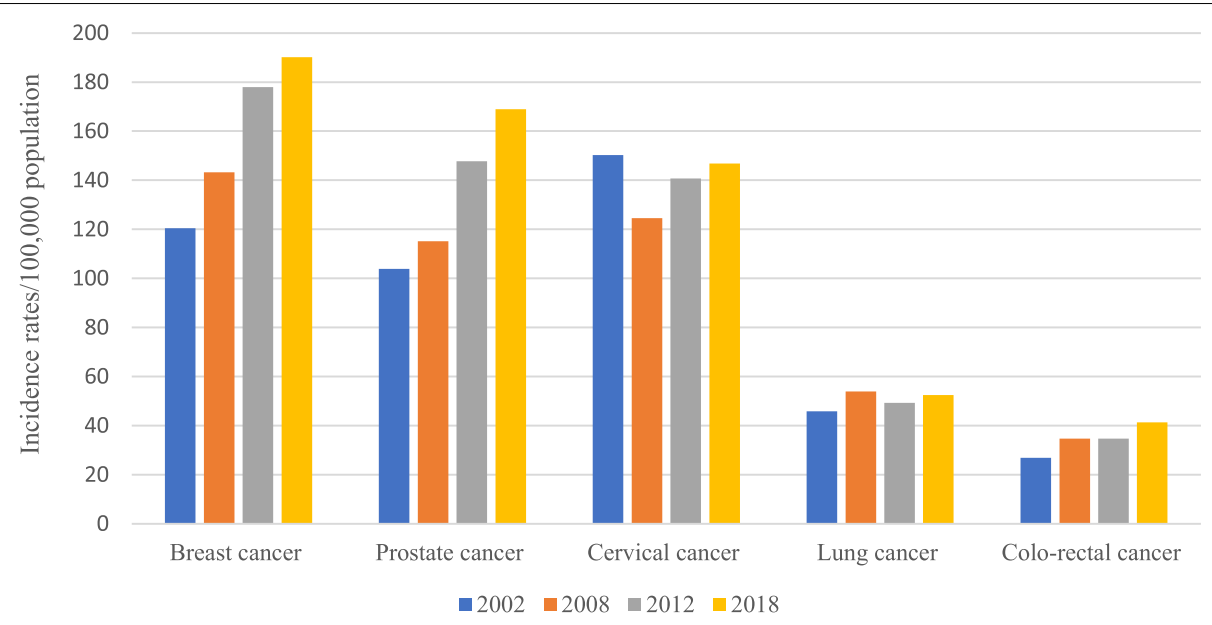

Fig. 2 Trends in the incidence rates (per 100,000 inhabitants) of the most prevalent cancers in Africa between 2002 and 2018 (GLOBOCAN reports; Global Cancer Statistics) [6] 
Clonal bone marrow plasma cells $>10 \%$ or biopsy-proven bony or extramedullary plasmacytoma and any one or more of the following $\mathrm{CRAB}$ features and myeloma-defining events:

1) Evidence of end organ damage that can be attributed to the underlying plasma cell proliferative disorder, specifically:

a) Hypercalcemia: serum calcium $>0.25 \mathrm{mmol} / \mathrm{L}$ $(>1 \mathrm{mg} / \mathrm{dL}$ ) higher than the upper limit of normal or $>2.75 \mathrm{mmol} / \mathrm{L}(>11 \mathrm{mg} / \mathrm{dL})$;

b) Renal insufficiency: creatinine clearance $<40 \mathrm{~mL}$ per minute or serum creatinine $>177 \mathrm{~mol} / \mathrm{L}(>2 \mathrm{mg} / \mathrm{dL})$; lowest limit of normal, or a hemoglobin value $<100 \mathrm{~g} / \mathrm{L}$;
2) Any one or more of the following biomarkers of malignancy (MDEs):

a) $60 \%$ or greater clonal plasma cells on bone marrow examination;

b) Serum involved / uninvolved free light chain ratio of 100 or greater, provided the absolute level of the involved light chain is at least $100 \mathrm{mg} / \mathrm{L}$ (a patient's involved free light chain either kappa or lambda is the one that is above the normal reference range; the uninvolved free light chain is the one that is typically in, or below, the normal range);

c) More than one focal lesion on MRI that is at least $5 \mathrm{~mm}$ or greater in size.

d) Bone lesions: one or more osteolytic lesion on skeletal radiography, $\mathrm{CT}$, or $\mathrm{PET} / \mathrm{CT}$. If bone marrow has $<10 \%$ clonal plasma cells, more than one bone lesion is required to distinguish from solitary plasmacytoma with minimal marrow involvement.

Fig. 3 IMWG revised multiple myeloma diagnostic criteria

\section{Challenges of multiple myeloma diagnosis across Africa Low clinician suspicion index, population awareness, and access to diagnostic services}

Multiple myeloma is preceded by an asymptomatic, silent premalignant condition called monoclonal gammopathy of undetermined significance (MGUS) and an intermediate stage in a small section of patients called smoldering multiple myeloma (SMM) [29, 32]. It is approximated that MGUS and SMM progress to full blown multiple myeloma at a rate of $1 \%$ and $10 \%$ per year respectively $[33,34]$. Due to the lack of routine screening for MGUS and SMM among the population at risk ( $>40$ years old) in almost all African countries, the two conditions are often accidentally diagnosed when increased monoclonal $(\mathrm{M})$ proteins are detected in patients being examined for different illnesses such as back pain linked to degenerative spine diseases, anemia, and renal failure linked to different systemic comorbidities, bone pain linked to polymyalgia rheumatica, or bone lesions and hypercalcemia linked to metastatic cancer originating from elsewhere [35]. Low suspicion index of MM among clinicians results into patients' initial symptoms being ignored or missed. Nwabuko and colleagues, in the Niger Delta, reported that majority of the MM patients diagnosed were referrals from the orthopedics, who presented with pathological fractures and were first managed by the orthopedic surgeons as skeletal-related events without making primary diagnosis [36].

Majority of MM patients at first hospital visit are attended to by primary care clinicians, outside the hematology unit [37]. Primary data on the awareness about signs and symptoms of MM among primary care clinicians in sub-Saharan Africa is scarce. Both Nwabuko et al. [38] in Nigeria and Oduor et al. [39] in Kenya reported very low clinician awareness about the signs and symptoms of MM, but without formal surveys, and attributed most of the late diagnoses observed to this challenge. Studies on the knowledge about cervical cancer screening among health care workers in Nigeria and Zimbabwe revealed an alarming majority of the health care workers did not know about screening for the cancer [40-42]. Cervical cancer is a very prevalent cancer in Africa and so it can be inferred that their knowledge on $\mathrm{MM}$ which is a relatively low-rate malignancy would 
equally be very low. Although the international myeloma foundation (IMF) designated March every calendar year as the international myeloma awareness and action month, activities to promote $\mathrm{MM}$ are not very visible in Africa. In Nigeria, the Princess Nikki foundation organizes an annual meeting involving between 12 and 18 spouses of the African heads of states and public health experts from the USA, Europe, and Africa to discuss cervical cancer and other cancers affecting women, while several other African countries, including Zambia, Ethiopia, Kenya, and South Africa, have utilized radio, television, and print media to promote cancer awareness, but multiple myeloma does not feature prominently in these awareness campaigns [43]. Country specific associations of oncologists and MM associations will have to deliberately and aggressively solicit for publicity to ensure the public is made aware of MM and its symptoms.

In addition to lack of awareness about MM, limited access to diagnostic facilities is another major challenge for MM patients. Acquah and colleagues [44] in Ghana studied 169 MM cases over a period of 14 years and reported that in the entire period, none of the cases was screened for MGUS or SMM. They further noted that $31.5 \%$ of the patients were diagnosed after 12 months of illness. This implies that in the 12-month period, these patients probably moved from one health facility to another seeking treatment yet none of the clinicians could suspect MM. Like most African countries, Ghana does not include screening for paraproteinemias on its routine health checks in primary care facilities; one is due to low prevalence of MM but secondly because of severe inadequacy of diagnostic facilities countrywide [44]. Ngouadjeu et al. [45] in agreement with this Ghana study also assessed 62 myeloma patients at a tertiary hospital in Cameroon, and discovered that $61.2 \%$ of them were diagnosed at stage III of the disease; a late diagnosis that is a predictor for poor prognosis. Okello et al. [46] in Uganda assessed records of $217 \mathrm{MM}$ patients over a period of 5 years at the Uganda Cancer Institute-a regional institute serving patients form the Democratic Republic of the Congo, South Sudan, Kenya, Tanzania, Burundi, and Rwanda-and found out that the center lacked key test procedures required in the workup of MM patients. For instance, majority of the patients did not have results for beta-2 microglobulin and immunofixation tests concurring with a similar study in Kenya where out of 194 patients assessed, only $52.6 \%$ had at least one radiology test done at diagnosis [47]. Furthermore, genetic aberrations, such as $t(4 ; 14), t(11 ; 14)$, monosomy $13 /$ del13q, and monosomy $17 /$ del17p, are known to be associated with poor prognosis in myeloma patients, and are routinely used to choose personalized chemotherapy options for specific groups of patients, and so gene profiling tests are routinely done. In this study, it was discovered that these tests are not available at the facility [46]. The above challenges indicate the stark differences in awareness and availability of diagnostic services for MM between highincome countries and low-resource settings which could account for the seemingly low prevalence of the cancer on the African continent.

\section{Prohibitive cost of diagnostic services}

Histopathology, cytology, and molecular tests required to diagnose multiple myeloma and other cancers in general are labor intensive and expensive [48]. While expenditure on laboratory services as a proportion of total healthcare expenditure in high-income countries range between 3 and 6\%, in sub-Saharan Africa, it is generally below 1\% apart from South Africa (3.5\%) and Uganda (3.3-4.6\%) [49-53]. Cancer care is primarily a function of government and faith-based hospitals across most African countries where diagnostic prices are subsidized. The challenge with public facilities across Africa is the gross inefficiencies and chronic shortage of essential cancer diagnostic supplies and drugs. A study by Boateng et al. in Ghana found out that $88 \%$ of essential cancer drugs and supplies were stocked out for a median duration of 70 days [54], while Martei et al. reported $40 \%$ stock out of essential cancer drugs in Botswana with a median duration of 30 days [55]. Similar situations have been noted in other countries across the continent. The WHO estimates that two-third of the world's population do not have access to basic diagnostic X-ray services while between 50 and $80 \%$ of all medical equipment in developing countries are non-functional, posing a significant challenge to cancer diagnosis, including multiple myeloma (MM) [56, 57]. The list of available essential radiology equipment for MM diagnosis by regions in Africa as compiled by WHO was extracted and presented in Tables 2, 3, 4, 5, and 6 [57]. Private sector players have adapted to fill the

Table 2 WHO essential radiology equipment for MM diagnosis by region (Central Africa)

\begin{tabular}{lllll}
\hline Country & CT & MRI & PET scan & Total \\
\hline Central African Rep & 0.00 & 0.00 & 0.00 & 0.00 \\
Dem. Rep. Congo & 0.07 & 0.00 & 0.00 & 0.07 \\
Gabon & 3.59 & 1.20 & 0.00 & 4.79 \\
Sao Tome and Principe & 0.00 & 0.00 & 0.00 & 0.00 \\
Chad & 0.08 & 0.00 & 0.00 & 0.08 \\
Cameroon & 0.63 & 0.04 & 0.00 & 0.67 \\
Eq. Guinea & 0.00 & 0.00 & 0.00 & 0.00 \\
Angola & 0.42 & 0.05 & 0.00 & 0.47 \\
Congo & 0.00 & 0.00 & 0.00 & 0.00 \\
\hline
\end{tabular}

Cancer Medical devices per 1,000,000 inhabitants in Central African region 
Table 3 WHO essential radiology equipment for MM diagnosis by region (Eastern Africa)

\begin{tabular}{lllll}
\hline Country & CT & MRI & PET scan & Total \\
\hline Eritrea & 0.32 & 0.16 & 0.00 & 0.48 \\
Mozambique & 0.00 & 0.00 & 0.00 & 0.00 \\
Kenya & 0.25 & 0.16 & 0.00 & 0.41 \\
Zambia & 0.21 & 0.07 & 0.00 & 0.28 \\
Mauritius & 6.43 & 4.82 & 0.00 & 11.25 \\
Ethiopia & 0.36 & 0.07 & 0.00 & 0.43 \\
Rwanda & 0.00 & 0.00 & 0.00 & 0.00 \\
Zimbabwe & 0.42 & 0.28 & 0.00 & 0.70 \\
Djibouti & 0.00 & 0.00 & 0.00 & 0.00 \\
Madagascar & 0.13 & 0.00 & 0.00 & 0.13 \\
Somalia & 0.00 & 0.00 & 0.00 & 0.00 \\
Comoros & 1.36 & 0.00 & 0.00 & 1.36 \\
Burundi & 0.20 & 0.00 & 0.00 & 0.20 \\
Tanzania & 0.12 & 0.04 & 0.02 & 0.18 \\
Uganda & 0.45 & 0.08 & 0.00 & 0.53 \\
Seychelles & 10.77 & 10.77 & 0.00 & 21.54 \\
Malawi & 0.31 & 0.06 & 0.00 & 0.37 \\
\hline
\end{tabular}

Cancer Medical devices per 1,000,000 inhabitants in Eastern African region

Table 4 WHO essential radiology equipment for MM diagnosis by region (Northern Africa)

\begin{tabular}{lllll}
\hline Country & CT & MRI & PET scan & Total \\
\hline S. Suan & 0.00 & 0.00 & 0.00 & 0.00 \\
Sudan & 1.13 & 0.32 & 0.00 & 1.45 \\
Egypt & 0.00 & 0.00 & 0.00 & 0.00 \\
Libya & 9.61 & 5.16 & 0.16 & 14.93 \\
Tunisia & 8.91 & 2.00 & 0.00 & 10.91 \\
Algeria & 0.00 & 0.00 & 0.00 & 0.00 \\
Morocco & 1.21 & 0.36 & 0.00 & 1.57 \\
\hline
\end{tabular}

Cancer Medical devices per 1,000,000 inhabitants in Northern African region

Table 5 WHO essential radiology equipment for MM diagnosis by region (Southern Africa)

\begin{tabular}{lllll}
\hline Country & CT & MRI & PET-scan & Total \\
\hline Lesotho & 0.00 & 0.00 & 0.00 & 0.00 \\
Namibia & 4.78 & 0.87 & 0.00 & 5.65 \\
Botswana & 0.99 & 0.49 & 0.00 & 1.48 \\
Eswatini & 2.40 & 0.00 & 0.00 & 2.40 \\
South Africa & 0.97 & 0.23 & 0.06 & 1.26 \\
\hline
\end{tabular}

Cancer Medical devices per 1,000,000 inhabitants in Southern African region

crucial gaps left during these intermittent stock outs of cancer supplies and break down of diagnostic equipment. Unlike public facilities, however, private diagnostic facilities require out of pocket payment which is often quite
Table 6 WHO essential radiology equipment for MM diagnosis by region (Western Africa)

\begin{tabular}{lllll}
\hline Country & CT & MRI & PET scan & Total \\
\hline Benin & 0.29 & 0.00 & 0.00 & 0.29 \\
Togo & 0.73 & 0.15 & 0.00 & 0.88 \\
Burkina Faso & 0.65 & 0.06 & 0.00 & 0.71 \\
Cabo Verde & 2.00 & 2.00 & 2.00 & 6.00 \\
Cote D'Ivoire & 0.69 & 0.15 & 0.00 & 0.84 \\
Mauritania & 1.54 & 0.77 & 0.00 & 2.31 \\
Mali & 0.20 & 0.00 & 0.00 & 0.20 \\
Senegal & 0.35 & 0.14 & 0.00 & 0.49 \\
Gambia & 1.08 & 0.54 & 0.00 & 1.62 \\
Ghana & 0.15 & 0.08 & 0.00 & 0.23 \\
Guinea & 0.00 & 0.00 & 0.00 & 0.00 \\
Nigeria & 0.00 & 0.00 & 0.00 & 0.00 \\
Niger & 0.17 & 0.00 & 0.00 & 0.17 \\
Guinea-Bissau & 0.00 & 0.00 & 0.00 & 0.00 \\
Sierra Leone & 0.33 & 0.00 & 0.00 & 0.33 \\
Liberia & 0.00 & 0.00 & 0.00 & 0.00 \\
\hline Cancer Medical devices per $1,000,000$ & inhabitants in Western African region
\end{tabular}

expensive for an average citizen. For instance, the standard MM diagnostic criteria as stated in Fig. 3 includes at least bone marrow biopsy, serum calcium and creatinine analysis, X-ray or CT scan, and immunoglobulin freelight chain analysis. Looking at the private diagnostic prices of these tests as estimated from Lancet laboratories LTD - a private diagnostic laboratory with branches in 12 countries across Africa-in Table 7, a patient will part with at least 156.6 USD to confirm their diagnosis $[58,59]$. Given that 490 million people, approximately $36 \%$ of Africans live in extreme poverty [60], it is almost certain that most patients will not afford this cost and hence never get diagnosed.

In the developed economies, national health insurances covers most if not all cancer care costs. In Africa, however, health insurance penetration is still low and varies widely among countries, e.g., while Rwanda as of 2017 had 87\% coverage, Nigeria had a mere 3\% in the same year, South Africa $17 \%$, Kenya $10 \%$, and Tanzania 3\% [61]. Most African countries employed the Bismarckian social health insurance systems, where mostly formal sector employees jointly contribute for coverage with the employer [62]. Recently, however, community-based health insurance schemes have been successfully piloted and implemented to cover the informal sector workers [63]. Unlike other diseases, cancer care is long-term and expensive, so private insurance players dodge them. In certain African countries, government interventions have at least increased cover for cancer care. For instance, in 2016, Kenya national insurance system boldly introduced 
Table 7 Multiple myeloma diagnostic tests and their average prices in the private sector

\begin{tabular}{|c|c|c|c|}
\hline Test name & Reason for test & Result in multiple myeloma & Avg cost (USD) \\
\hline Bone marrow biopsy & $\begin{array}{l}\text { 1. Examine the appearance, size, shape and } \\
\text { arrangement of the cells } \\
\text { 2. Determine presence of myeloma cells } \\
\text { and their number. }\end{array}$ & Confirm myeloma cells & 40.3 \\
\hline $\begin{array}{l}\text { Bone marrow aspirate for the following: } \\
\text { 1. Immunohistochemistry } \\
\text { 2. Flow cytometry } \\
\text { 3. Cytogenetics } \\
\text { 4. Fluorescent in situ hybridization (FISH) }\end{array}$ & $\begin{array}{l}\text { a. Immunohistochemistry helps to identify } \\
\text { myeloma cells } \\
\text { b. Flow cytometry determines if cells are } \\
\text { abnormal and if they are myeloma, lym- } \\
\text { phoma, other cancers or non-cancerous. } \\
\text { c. Cytogenetics determines abnormality in } \\
\text { chromosomes } \\
\text { d. FISH determines chromosomal changes } \\
\text { and changes too small to be seen by } \\
\text { cytogenetic testing. }\end{array}$ & $\begin{array}{l}\text { Confirm myeloma cells and chromosomal } \\
\text { abnormalities }\end{array}$ & 419 \\
\hline Complete blood count (CBC) & $\begin{array}{l}\text { Determines cell count especially RBC } \\
\text { count for anemia. }\end{array}$ & Anemia & 12.2 \\
\hline $\begin{array}{l}\text { Blood chemistry tests } \\
\text { 1. Serum creatinine } \\
\text { 2. Serum albumin } \\
\text { 3. Calcium } \\
\text { 4. Lactic dehydrogenase (LDH) }\end{array}$ & $\begin{array}{l}\text { 1. Creatinine to show how well the kidneys } \\
\text { are working } \\
\text { 2. Albumin is found in blood } \\
\text { 3. Calcium levels determines stage } \\
\text { 4. LDH indicates prognosis }\end{array}$ & $\begin{array}{l}\text { High } \\
\text { Low } \\
\text { High in advanced myeloma } \\
\text { High in advanced myeloma }\end{array}$ & $\begin{array}{l}6.7 \\
8.6 \\
8.6 \\
8.6\end{array}$ \\
\hline $\begin{array}{l}\text { 24-h urine test } \\
\text { 1. Urine electrophoresis } \\
\text { 2. Urine immunofixation }\end{array}$ & $\begin{array}{l}\text { Determine Bence Jones protein, and } \\
\text { monoclonal antibodies in urine }\end{array}$ & Present and high concentration & $\begin{array}{l}28.5 \\
28.5\end{array}$ \\
\hline Quantitative immunoglobulins & $\begin{array}{l}\text { Determine changes in the levels of } \lg A \text {, } \\
\lg D, \lg E, \lg G \text {, and } \lg M \text { proteins }\end{array}$ & $\begin{array}{l}\text { High levels of one type while others } \\
\text { remain low. }\end{array}$ & 111 \\
\hline Serum protein electrophoresis (SPEP) & $\begin{array}{l}\text { Measures the antibodies in blood and can } \\
\text { find a monoclonal antibody }\end{array}$ & M spike & 26.7 \\
\hline Serum-free light chains & $\begin{array}{l}\text { Used in in rare cases of myeloma where } \\
\text { no M protein is found by SPEP. Since SPEP } \\
\text { measures levels of intact (whole) antibod- } \\
\text { ies, it cannot measure the amount of light } \\
\text { chains only. }\end{array}$ & $\begin{array}{l}\text { Increased Kappa: lambda ratio (normal is } \\
1: 1 \text { ) }\end{array}$ & 78.8 \\
\hline Beta-2 microglobulin & An indicator of prognosis & High in advanced myeloma & 28 \\
\hline \multicolumn{4}{|l|}{ Imaging tests } \\
\hline Bone X-ray & $\begin{array}{l}\text { Detects destruction caused by myeloma } \\
\text { cells }\end{array}$ & Bone destruction & 15 \\
\hline CT scan & $\begin{array}{l}\text { Detects bone destruction and guides } \\
\text { biopsy }\end{array}$ & Bone destruction & 90 \\
\hline Magnetic resonance imaging (MRI) & $\begin{array}{l}\text { Detailed images can find plasmacytomas } \\
\text { not seen on regular X-rays }\end{array}$ & - & 200 \\
\hline $\begin{array}{l}\text { Positron emission tomography (PET) } \\
\text { scan }\end{array}$ & $\begin{array}{l}\text { Looks for other plasmacytomas in a patient } \\
\text { appearing to have a single plasmacytoma. }\end{array}$ & - & 150 \\
\hline
\end{tabular}

Costs of essential multiple myeloma diagnostic tests as determined by Lancet Laboratories LTD, a private pathology laboratory operating in over 12 countries across South, East, and West Africa [43]

cancer care package for the $18 \%$ of Kenyans it covers [64]. Similarly, Rwanda's Mutuelle de Santé, the national health insurance scheme reimburses all cancer care costs [64]. While Botswana in 2015 incorporated $80 \%$ of the cancer medications added onto the WHO essential medicines list into their national essential medicines list, essentially making them free for all cancer patients who need them [64]. To improve multiple myeloma diagnosis on the continent, such bold moves must be replicated by other African governments to ease the burden of out-of-pocket payments on the cancer patients and encourage early diagnosis.

\section{Shortage of human resource (pathologists, histotechnologists, and cytotechnologists)}

Multiple myeloma diagnosis just like other cancers is provided by a medically trained pathologist with support from non-medically trained scientist histotechnologists and cytotechnologists. The histotechnologists and cytotechnologists provide the technical expertise required 
to process tissue and fluid specimens in preparation for examination by the pathologists [48]. Across Sub-Saharan Africa, due to the chronic shortage of pathologists, cancer care is only offered at the national referral hospitals which are often in the capital cities, creating a significant barrier in terms of access to care by patients in the country sides. It is estimated that the ratio of pathologist to patient in Sub-Saharan Africa is 1:1,000,000 compared to $1: 25,000$ in the USA or 1:36,000 in the UK [65]. In Cameroon, by 2016, the number of pathologists to patients was estimated to be $0.28: 1,000,000$ while that of cytotechnologists was $0.23: 1,000,000$ [66]. Similarly, in Zambia by 2009 , there were less than 10 anatomic pathologists in the whole country, a ratio of 1:1,400,000 inhabitants at a time when the UK had over 1800 anatomic pathologists serving 66 million people at a ratio of 1:36,000 inhabitants [65]. The highest recorded ratio of pathologist to patient in Africa is 4.45:1,000,000 in South Africa, still grossly insufficient [67]. The dire implication of these figures is that it becomes virtually impossible to decentralize cancer care, as a result to the relatively lowrate cancers like multiple myeloma are never prioritized.

The future of the pathology work force in Africa is not certain either. By 2013, only 168 medical schools existed in 47 Sub-Saharan African countries surveyed; 24 of these countries had a single medical school while 11 had none [68]. Furthermore, the total number of students graduated by these medical schools is extremely low for the population they serve, with only a handful proceeding to pursue a career in pathology [69]. It is "comically" estimated that at this rate it will take over 400 years for Sub-Saharan Africa to match the pathologist to patient ratio of the USA and UK [48]. In addition to the lack of pathologist training, many Sub-Saharan African countries also do not have training programs for medical laboratory scientists, cytotechnologists, histotechnologists, and biomedical engineers required to maintain diagnostic equipment [70]. Often times where pathologist trainings exist, they are not aligned with the training of histotechnologists and cytotechnologists who are required to support pathologists in cancer diagnosis. Inadequate human resource is thus a huge barrier to multiple myeloma diagnosis across the continent and must be prioritized for diagnosis to improve.

Attempts to solve the dire shortage of pathologists have led to some ingenious solutions in certain African countries. For instance, in Cameroon, one faith-based hospital, piloted the use of histopathology slide scanners to take pictures of stained slides and electronically submit to a remote pathologist to make diagnosis [71]. Though a step in the right direction, still sample preparation requires trained laboratory scientists, cytotechnologists, and histotechnologists to carry out, in addition to a well-equipped histopathology laboratory capable of performing hematoxylin and eosin staining, and some special staining techniques. Preparation of histopathology slides require at least $12 \mathrm{~h}$ of uninterrupted power supply. In this project, the hospital reported frequent power cuts-a notorious challenge across Sub-Saharan Africathat often forced the technicians to finish the process manually or repeat the entire procedure, hence, causing substantial delays in diagnosis. Secondly, huge amounts of internet data are required per day ( $5 \mathrm{~GB})$, to submit the results coupled with poor internet connectivity in the area, another substantial challenge across the continent [71]. The challenges notwithstanding this method if well harnessed can in the short term solve the shortage of onsite pathologists and should be encouraged.

Collaborations among African oncologists' associations, their European and American counterparts, Universities and Pharmaceutical companies to conduct scientific research, short- and long-term capacity building trainings, and research fellowships, are some of the tried and tested strategies used to build capacity of African scientist and oncologists to manage certain cancers. Examples of such collaborations include Men of African Descent and Carcinoma of the Prostate (MADCaP) consortium having multiple centers in Senegal, Ghana, Nigeria, Sudan, Uganda, Botswana, and South Africa; Women of African Ancestry Breast Cancer Consortium operational in Nigeria, Ghana, Cameroon, Uganda, and Senegal; and the Operation Stop Cervical Cancer Nigeria-a multilateral collaboration of the MD Anderson Cancer Center, British Columbia Cancer Agency, Rice University Department of Bioengineering, and the University of Ibadan School of Medicine. African associations of multiple myeloma oncologists and care givers could thus seek such collaborations to ensure trainings for more MM dedicated oncologists and care givers and mobilization of funds for setting up more diagnostic infrastructures [72-75].

\section{Conclusion}

In a nutshell, therefore, the challenges to multiple myeloma diagnosis in Sub-Saharan Africa are mainly in three categories: low suspicion index among clinicians and limited access to diagnostic services resulting into missed diagnosis; high cost of private diagnostic services that complements the scarce public care, hindering patients' ability to seek early care or afford the available tests required and; chronic shortage of human resource (pathologists, histotechnologists, and cytotechnologists), making it impossible to scale up and decentralize care. These are challenges that require a systems approach to thinking among policy makers, philanthropic organizations and the clinicians at the forefront of multiple 
myeloma care. It is thus important that the necessary investments in both infrastructure and human resource are made, more research conducted to ascertain local burden of the cancer and in the meantime, clinicians made aware of the cardinal signs of MM through continuous medical education so that maximizing the available diagnostic capability, they can start seriously considering $\mathrm{MM}$ in the differential diagnosis of cases presenting as such.

\section{Possible solutions and future prospects}

Across all the studies reviewed above, bone pain (61.995.0\%), anemia, and renal insufficiency were the major complaints at presentation in MM patients [44-46]. If primary care physicians are made aware of these cardinal signs of the disease, incorporating MM suspicion in the differential diagnosis of patients with such complaints will drastically improve its surveillance and case notification. This goes in tandem with research into the local incidence and prevalence of the disease to offer objective basis for including $\mathrm{MM}$ in the differential diagnosis of patients with the above symptoms at presentation.

When African presidents met in Abuja, Nigeria, in April 2001, they committed to allocating $15 \%$ of their total budget to health [76]. This should not stop in rhetorics but fully implemented. Compared to high income countries that spend over $\$ 4000$ per capita on health, African countries spend between $\$ 8$ and $\$ 129$, a drop in the ocean. The WHO estimates that about 100 million people are pushed into extreme poverty every year due to out-of-pocket spending on healthcare [77]. Such spending forces patients to underinvest in treatment creating situations where they opt to avoid diagnostic services as they do not see immediate value in diagnostics compared to treatment. Therefore, the WHO's call for universal health coverage must be echoed louder if we are to see improvements in multiple myeloma diagnosis and care. Government investment, private insurance, and key philanthropic partnerships such as the 2017 American Cancer Society and the Clinton Health Access Initiative agreement with pharmaceutical companies to bring down the cost of essential cancer drugs should be explored in areas of diagnostics [78]. This will ensure the most vulnerable multiple myeloma patients get access to the diagnostic services they urgently need.

Lastly, solving the challenge of shortage of skilled human resource such as pathologists will require massive investment in medical training and offering pathologists competitive renumeration packages to keep them in public service. These are long-term goals that governments across the continent must not shy away from as there is no quick fix. In the meantime, creative solutions such as leveraging technological advances (digital pathology) to connect onsite labs with offsite pathologists as seen in Cameroon, online training via Skype as seen in Nigeria [64], and collaborations with universities and pharmaceuticals for capacity building will go a long way in solving the human resource shortages.

\section{Abbreviations}

MM: Multiple myeloma; CRAB: Calcium (elevated), renal failure, anemia, bone lesions; USA: United States of America; MGUS: Monoclonal gammopathy of undetermined significance; SMM: Smoldering multiple myeloma; IMWG: International Myeloma Working Group; UK: United Kingdom; AFCRN: African Cancer Registry Network; WHO: World Health Organization.

\section{Acknowledgements}

Ms. Giramia Oliver: Reviewed the manuscript and provided grammatical corrections

\section{Authors' contributions}

ET conceived the study, conducted article and data search, and wrote the draft manuscript. CN participated in data search and reviewed the manuscript. AOA reviewed the manuscript. The authors read and approved the final manuscript.

\section{Funding}

No funding was provided for this study.

\section{Availability of data and materials}

All data generated or analyzed during this study are included in this article [and its supplementary information files].

\section{Declarations}

Ethics approval and consent to participate

Not applicable

\section{Consent for publication}

Not applicable

\section{Competing interests}

All authors declare that they have no competing interests.

\section{Author details}

${ }^{1}$ Program and Department of Clinical Laboratory Medicine, Center for Gene Diagnosis, Zhongnan Hospital of Wuhan University, Wuhan 430071, China.

${ }^{2}$ Department of Radiology and Nuclear Medicine, Zhongnan Hospital of Wuhan University, Wuhan 430071, China. ${ }^{3}$ Department of Oncology, Zhongnan Hospital of Wuhan University, Wuhan 430071, China.

Received: 3 October 2021 Accepted: 23 November 2021

Published online: 11 December 2021

\section{References}

1. Talamo G, Farooq U, Zangari M, Liao J, Dolloff NG, Loughran TP et al (2010) Beyond the CRAB symptoms: a study of presenting clinical manifestations of multiple myeloma. Clin Lymphoma Myeloma Leukemia 10(6):464-468. https://doi.org/10.3816/CLML.2010.n.080

2. Dispenzieri A, Kyle RA (2005) Multiple myeloma: clinical features and indications for therapy. Best Pract Res Clin Haematol 18(4):553-568. https://doi.org/10.1016/j.beha.2005.01.008

3. National Cancer Institute Visuals Online. (2014). Multiple myeloma. https://visualsonline.cancer.gov/details.cfm?imageid=9840 Accessed 3 Aug 2021. 
4. Alao OO, Bazuaye GN, Halim NK, Omoti CE (2010) The epidemiology of haematological malignancies at the University of Benin teaching hospital: a ten-year retrospective study. Int J Epidemiol 9(2)

5. Rajkumar SV (2019) In: Kyle RA, Connor RF (eds) Staging and prognostic studies in multiple myeloma: UpToDate. UpToDate Inc

6. International Agency for Research on Cancer. (2021). Cancer Today. https://gco.iarc.fr/today/home

7. World Health Organization. https://apps.who.int/gho/data/view.main. POP2020?lang=en Accessed 3 Aug 2021.

8. Cohen HJ (2006) Prevalence of monoclonal gammopathy of undetermined significance. N Engl J Med 354(26):2832. https://doi.org/10.1056/ NEJMc061160

9. Singh J, Dudley AW Jr, Kulig KA (1990) Increased incidence of monoclonal gammopathy of undetermined significance in blacks and its age-related differences with whites on the basis of a study of 397 men and one woman in a hospital setting. J Lab Clin Med 116(6):785-789

10. Landgren O, Weiss BM (2009) Patterns of monoclonal gammopathy of undetermined significance and multiple myeloma in various ethnic/ racial groups: support for genetic factors in pathogenesis. Leukemia 23(10):1691-1697. https://doi.org/10.1038/leu.2009.134

11. Landgren O, Graubard BI, Kumar S, Kyle RA, Katzmann JA, Murata K et al (2017) Prevalence of myeloma precursor state monoclonal gammopathy of undetermined significance in 12372 individuals 10-49 years old: a population-based study from the National Health and nutrition examination survey. Blood Cancer J 7(10):e618. https://doi.org/10.1038/bcj.2017. 97

12. Landgren O, Gridley G, Turesson I, Caporaso NE, Goldin LR, Baris D et al (2006) Risk of monoclonal gammopathy of undetermined significance (MGUS) and subsequent multiple myeloma among African American and white veterans in the United States. Blood 107(3):904-906. https://doi. org/10.1182/blood-2005-08-3449

13. Bourguet CC, Grufferman S, Delzell E, DeLong ER, Cohen HJ (1985) Multiple myeloma and family history of cancer. A case-control study. Cancer 56(8):2133-2139 (https://doi.org/10.1002/1097-0142(19851015)56:8< 2133::aid-cncr2820560842>3.0.co;2-f)

14. Brown LM, Linet MS, Greenberg RS, Silverman DT, Hayes RB, Swanson GM et al (1999) Multiple myeloma and family history of cancer among blacks and whites in the U.S. Cancer 85(11):2385-2390

15. Cannon-Albright LA, Thomas A, Goldgar DE, Gholami K, Rowe K, Jacobsen M et al (1994) Familiality of cancer in Utah. Cancer Res 54(9):2378-2385

16. Ogmundsdóttir HM, Haraldsdóttirm V, Jóhannesson GM, Olafsdóttir $G$, Bjarnadóttir K, Sigvaldason H, Tulinius H (2005) Familiality of benign and malignant paraproteinemias. A population-based cancer-registry study of multiple myeloma families. Haematologica 90(1):66-71

17. Eriksson M, Hallberg B (1992) Familial occurrence of hematologic malignancies and other diseases in multiple myeloma: a case-control study. Cancer Causes Control 3:63-67

18. Hemminki K (2002) Re: familial multiple myeloma: a family study and review of the literature. J Natl Cancer Inst 94(6):462-463. https://doi.org/ 10.1093/jnci/94.6.462

19. Hemminki K, Vaittinen $P$ (1998) National database of familial cancer in Sweden. Genet Epidemiol 15(3):225-236 (https://doi.org/10.1002/(SICI) 1098-2272(1998)15:3<225::AID-GEPI2>3.0.CO;2-3)

20. Lynch HT, Watson P, Tarantolo S, Wiernik PH, Quinn-Laquer B, Bergsagel I et al (2005) Phenotypic heterogeneity in multiple myeloma families. J Clin Oncol 23(4):685-693. https://doi.org/10.1200/JCO.2005.10.126

21. Benjamin M, Reddy S, Brawley OW (2003) Myeloma and race: a review of the literature. Cancer Metastasis Rev 22(1):87-93. https://doi.org/10. 1023/a:1022268103136

22. Brown LM, Pottern LM, Silverman DT, Schoenberg JB, Schwartz AG, Greenberg RS et al (1997) Multiple myeloma among blacks and whites in the United States: role of cigarettes and alcoholic beverages. Cancer Causes Contr 8(4):610-614. https://doi.org/10.1023/a:1018498414298

23. Brown LM, Gridley G, Check D, Landgren O (2008) Risk of multiple myeloma and monoclonal gammopathy of undetermined significance among white and black male United States veterans with prior autoimmune, infectious, inflammatory, and allergic disorders. Blood 111(7):3388-3394. https://doi.org/10.1182/blood-2007-10-121285

24. Landgren O, Katzmann JA, Hsing AW, Pfeiffer RM, Kyle RA, Yeboah ED et al (2007) Prevalence of monoclonal gammopathy of undetermined significance among men in Ghana. Mayo Clin Proc 82(12):1468-1473. https://doi.org/10.1016/S0025-6196(11)61089-6

25. Ludwig H, Novis Durie S, Meckl A, Hinke A, Durie B (2020) Multiple myeloma incidence and mortality around the globe; interrelations between health access and quality, economic resources, and patient empowerment. Oncologist 25(9):e1406-e1413. https://doi.org/10.1634/ theoncologist.2020-0141

26. Curado MP, Edwards B, Shin HR et al (eds) (2007) Cancer incidence in five continents, volume IX. International Agency for Research on Cancer, Lyon

27. African Cancer Registry Network. http://afcrn.org (Accessed 28 Sep 2021)

28. Hamdi Y, Abdeljaoued-Tej I, Zatchi AA, Abdelhak S, Boubaker S, Brown JS, Benkahla A (2021) Cancer in Africa: the untold story. Front Oncol 11:650117. https://doi.org/10.3389/fonc.2021.650117

29. Landgren O, Kyle RA, Pfeiffer RM, Katzmann JA, Caporaso NE, Hayes RB et al (2009) Monoclonal gammopathy of undetermined significance (MGUS) consistently precedes multiple myeloma: a prospective study. Blood 113(22):5412-5417. https://doi.org/10.1182/blood-2008-12-194241

30. Parkin DM, Nambooze S, Wabwire-Mangen F, Wabinga HR (2010) Changing cancer incidence in Kampala, Uganda, 1991-2006. Int J Cancer 126(5):1187-1195. https://doi.org/10.1002/ijc.24838

31. Rajkumar SV, Dimopoulos MA, Palumbo A, Blade J, Merlini G, Mateos MV et al (2014) International myeloma working group updated criteria for the diagnosis of multiple myeloma. Lancet Oncol 15(12):e538-e548. https://doi.org/10.1016/S1470-2045(14)70442-5

32. Weiss BM, Abadie J, Verma P, Howard RS, Kuehl WM (2009) A monoclonal gammopathy precedes multiple myeloma in most patients. Blood 113(22):5418-5422. https://doi.org/10.1182/blood-2008-12-195008

33. Kyle RA, Remstein ED, Therneau TM, Dispenzieri A, Kurtin PJ, Hodnefield, et al. (2007) Clinical course and prognosis of smoldering (asymptomatic) multiple myeloma. N Engl J Med 356(25):2582-2590. https://doi.org/10. 1056/NEJMoa070389

34. Kyle RA, Therneau TM, Rajkumar SV, Offord JR, Larson DR, Plevak MF, Melton LJ 3rd (2002) A long-term study of prognosis in monoclonal gammopathy of undetermined significance. N Engl J Med 346(8):564-569. https://doi.org/10.1056/NEJMoa01133202

35. Bergstrom DJ, Kotb R, Louzada ML, Sutherland HJ, Tavoularis S, Venner CP, Myeloma Canada Research Network Consensus Guideline Consortium (2020) Consensus quidelines on the diagnosis of multiple myeloma and related disorders: recommendations of the myeloma Canada research network consensus guideline consortium. Clin Lymphoma Myeloma Leukemia 20(7):e352-e367. https://doi.org/10.1016/j.clml.2020.01.017

36. Nwabuko OC, Igbigbi EE, Chukwuonye II, Nnoli MA (2017) Multiple myeloma in Niger Delta, Nigeria: complications and the outcome of palliative interventions. Cancer Manag Res 9:189-196. https://doi.org/10. 2147/CMAR.S126136

37. Bird J, Behrens J, Westin J, Turesson I, Drayson M, Beetham R et al (2009) UK myeloma forum (UKMF) and Nordic myeloma study group (NMSG): guidelines for the investigation of newly detected $\mathrm{M}$-proteins and the management of monoclonal gammopathy of undetermined significance (MGUS). Br J Haematol 147(1):22-42. https://doi.org/10.1111/j.1365-2141. 2009.07807.x

38. Nwabuko CO, Nnoli MA, Igbigbi EE (2015) Plasma cell [8] myeloma: challenges in diagnosis in sub-Saharan Africa. Jokull J 65(1):254-266

39. Oduor MA, Lotodo TC, Vik TA, Manyega KM, Loehrer P, Omondi A et al (2021) Building a sustainable comprehensive multiple myeloma program in Western Kenya. JCO Glob Oncol 7:400-407. https://doi.org/10.1200/ GO.20.00572

40. Tarwireyi F, Chirenje ZM, Rusakaniko S (2003) Cancer of the cervix: knowledge, beliefs and screening behaviours of health workers in Mudzi District in Mashonaland East Province, Zimbabwe. Central Afr J Med 49(7-8):83-86

41. Ayinde OA, Omigbodun AO (2003) Knowledge, attitude and practices related to prevention of cancer of the cervix among female health workers in Ibadan. J Obstetr Gynaecol 23(1):59-62. https://doi.org/10.1080/ 0144361021000043272

42. Anya SE, Oshi DC, Nwosu SO, Anya AE (2005) Knowledge, attitude, and practice of female health professionals regarding cervical cancer and pap smear. Nigerian J Med 14(3):283-286

43. Ahmedin J, Brawley Otis W (2019) Increasing cancer awareness and prevention in Africa. E Cancer 13:939 
44. Acquah ME, Hsing AW, McGuire V, Wang S, Birmann B, Dei-Adomakoh Y (2019) Presentation and survival of multiple myeloma patients in Ghana: a review of 169 cases. Ghana Med J 53(1):52-58. https://doi.org/10.4314/ gmj.v53i1.8

45. Tsakeu Eveline ND (2018) Multiple myeloma in Cameroon: clinico-biological characteristics patients; an experience from Douala general hospital. Haematol Int J 2(1). https://doi.org/10.23880/HIJ-16000113

46. D. C, Mulumba Y, Omoding A, Ddungu H, Welch KL, Thompson et al (2021) Characteristics and outcomes of patients with multiple myeloma at the Uganda cancer institute. Afr Health Sci 21(1):67-74. https://doi.org/ 10.4314/ahs.v21i1.11

47. Manyega KM, Lotodo TC, Oduor MA, Namaemba DF, Omondi AA, Oyolo, et al. (2021) Retrospective analysis of presentation, treatment, and outcomes of multiple myeloma at a large public referral hospital in Eldoret, Kenya. JCO Glob Oncol 7:391-399. https://doi.org/10.1200/GO.20.00573

48. Wilson ML, Fleming KA, Kuti MA, Looi LM, Lago N, Ru K (2018) Access to pathology and laboratory medicine services: a crucial gap. Lancet (London, England) 391(10133):1927-1938. https://doi.org/10.1016/S01406736(18)30458-6

49. Avivar C (2012) Strategies for the successful implementation of viral laboratory automation. Open Virol J 6:115-121. https://doi.org/10.2174/ 1874357901206010115

50. Carter P (2008) Report of the second phase of the review of NHS pathology services in England. Department of Health, London http://webar chive.nationalarchives.gov.uk/20130124044941/http://www.dh.gov.uk/ prod_consum_dh/groups/dh_digitalassets/@dh/@en/documents/digit alasset/dh_091984.pdf Accessed 16 Aug 2021

51. Centre for International Economics (2016) The economic value of pathology: achieving better health, and a better use of health resources. Centre for International Economics, Canberra and Sydney http://www.thecie. com.au/wpcontent/uploads/2016/04/Economicvalueofpathology_Final ReportApril2016.pdf Accessed 16 Aug 2021

52. Pillay TS (2012) Containing costs in the era of National Health Insurance - the need for and importance of demand management in laboratory medicine. South Afr Med J 103(1):24. https://doi.org/10.7196/samj.6383

53. Schroeder LF, Elbireer A, Jackson JB, Amukele TK (2015) Laboratory diagnostics market in East Africa: a survey of test types, test availability, and test prices in Kampala, Uganda. PLoS One 10(7):e0134578. https://doi. org/10.1371/journal.pone.0134578

54. Boateng R, Renner L, Petricca K, Gupta S, Denburg A (2020) Health system determinants of access to essential medicines for children with cancer in Ghana. BMJ Glob Health 5(9):e002906. https://doi.org/10.1136/ bmjgh-2020-002906

55. Martei YM, Chiyapo S, Grover S, Ramogola-Masire D, Dryden-Peterson S, Shulman LN, Tapela N (2018) Availability of WHO essential medicines for cancer treatment in Botswana. J Glob Oncol 4:1-8. https://doi.org/10. 1200/JGO.17.00063

56. World Health Organization (2012) Local production and technology transfer to increase access to medical devices, Geneva

57. WHO Essential diagnostic imaging. World Health Organization https:// web.archive.org/web/20121023154427/http://www.who.int/eht/en/ Diagnosticlmaging.pdf Accessed 3 Aug 2021

58. Lancet Laboratories LTD (2020) Price catalogue, pathologists Lancet Kenya https://lancet.co.ke/wp-content/uploads/2020/05/Price-Catal ogue-2020.pdf Accessed 26 Sep 2021

59. Myeloma Crowd by Health Tree. How is multiple myeloma diagnosed? https://www.myelomacrowd.org/how-is-myeloma-diagnosed/ Accessed 26 Sep 2021

60. Development Aid. (2021). African countries continue to have the highest poverty rates in the world. https://www.developmentaid.org/\#!/newsstream/post/84943/highest-poverty-rates-in-africa Accessed 26 Sep 2021

61. University of Michigan (2021) The future of universal health coverage in Africa. School of Public Health, University of Michigan. https://sph.umich. edu/pursuit/2021 posts/future-of-universal-health-coverage-in-africa. html Accessed 26 Sep 2021
62. Criel B, Van Dormael M (1999) Mutual health organizations in Africa and social health insurance systems: will European history repeat itself? Trop Med Int Health 4(3):155-159. https://doi.org/10.1046/j.1365-3156.1999. 43385.x

63. Carapinha JL, Ross-Degnan D, Desta AT, Wagner AK (2011) Health insurance systems in five sub-Saharan African countries: medicine benefits and data for decision making. Health Policy (Amsterdam, Netherlands) 99(3):193-202. https://doi.org/10.1016/j.healthpol.2010.11.009

64. (2018) Taking up Africa's cancer challenge. Bull World Health Organ 96(4):229-230. https://doi.org/10.2471/BLT.18.020418

65. Mudenda V, Malyangu E, Sayed S, Fleming K (2020) Addressing the shortage of pathologists in Africa: creation of a MMed programme in pathology in Zambia. Afr J Lab Med 9(1):974. https://doi.org/10.4102/ajlm.v9i1. 974

66. Myeloma Crowd by Health Tree. (2021). How is multiple myeloma diagnosed? https://www.myelomacrowd.org/how-is-myeloma-diagnosed/

67. African Strategies for Advancing Pathology Group, Mutuku A: Online survey of pathology capacity in Sub-Saharan Africa (SSA), in African Strategies for Advancing Pathology Annual Report. 2016. www.patho logyinafrica.org Google Scholar

68. Mullan F, Frehywot S, Omaswa F, Buch E, Chen C, Greysen SR et al (2011) Medical schools in sub-Saharan Africa. Lancet (London, England) 377(9771):1113-1121. https://doi.org/10.1016/S0140-6736(10)61961-7

69. Chen C, Buch E, Wassermann T, Frehywot S, Mullan F, Omaswa F et al (2012) A survey of sub-Saharan African medical schools. Hum Resour Health 10:4. https://doi.org/10.1186/1478-4491-10-4

70. Nelson AM, Milner DA, Rebbeck TR, Iliyasu Y (2016) Oncologic care and pathology resources in Africa: survey and recommendations. J Clin Oncol Off J Am Soc Clin Oncol 34(1):20-26. https://doi.org/10.1200/JCO.2015. 61.9767

71. Gruber-Mösenbacher U, Katzell L, McNeely M, Neier E, Jean B, Kuran A, Chamala S (2021) Digital pathology in Cameroon. JCO Glob Oncol 7:1380-1389. https://doi.org/10.1200/GO.21.00166

72. Garner CP, Ding YC, John EM, Ingles SA, Olopade OI, Huo D et al (2008) Genetic variation in IGFBP2 and IGFBP5 is associated with breast cancer in populations of African descent. Hum Genet 123(3):247-255. https:// doi.org/10.1007/s00439-008-0468-X

73. Miller D, Okolo CA, Mirabal Y, Guillaud M, Arulogun OS, Oladepo O et al (2007) Knowledge dissemination and evaluation in a cervical cancer screening implementation program in Nigeria. Gynecol Oncol 107(1 Suppl 1):S196-S207. https://doi.org/10.1016/j.ygyno.2007.07.014

74. Oladokun A, Morhason-Bello IO, Bello FA, Adewole IF (2010) The learning curve of radical hysterectomy for early cervical carcinoma. Afr J Med Med Sci 39(4):329-332

75. University of Michigan. (2021). The future of universal health coverage in Africa. School of Public Health, University of Michigan. https://sph.umich. edu/pursuit/2021 posts/future-of-universal-health-coverage-in-africa. html Accessed 2 July 2021

76. United Nations. (2020). Public financing for health in Africa: $15 \%$ of an elephant is not $15 \%$ of a chicken. United Nations General Assembly. https://www.un.org/africarenewal/magazine/october-2020/public-finan cing-health-africa-when-15-elephant-not-15-chicken Accessed 3 Aug 2021

77. WHO. (2020) Universal Health Coverage. https://www.who.int/healthtopics/universal-health-coverage\#tab=tab_1 Accessed 3 Aug 2021

78. Clinton Health Access Initiative. (2020). New agreements to lower prices and increase access to lifesaving cancer treatment in sub-Saharan Africa. https://www.clintonhealthaccess.org/agreements-to-increase-access-tocancer-treatment-in-africa/ Accessed 3 Aug 2021

\section{Publisher's Note}

Springer Nature remains neutral with regard to jurisdictional claims in published maps and institutional affiliations. 